\title{
Carbetocin versus oxytocin and ergometrine for prevention of postpartum hemorrhage following caesarean section
}

\author{
Original \\ Article
}

\author{
Eman Zein El Abdeen MD, and Nesreen A. A. Shehata MD
}

Department of Obstetrics and Gynecology, Faculty of Medicine, Beni-Suef University, Egypt

\begin{abstract}
Objective: To compare the effectiveness of carbetocin versus oxytocin and ergometrine when administered after caesarean section for prevention of postpartum hemorrhage (PPH).

Patients and Methods: A prospective randomized observational study in the year 2014 was conducted on 200 women at term undergoing elective cesarean section under regional anesthesia. Women with pre term gestational age, diabetes, hypertension and coronary heart disease were excluded. Women were put into two groups : One group containing 100 women received I.V. carbetocin 100 microgram, while the other group which also contained 100 women received a combination of I.V. oxytocin 5 IU and I.M. Ergometrine $0.2 \mathrm{mg}$ after the delivery of the baby. The primary outcome measure: 1-Uterine tone and size were assessed by resting a hand on the fundus of uterus and palpating anterior wall of the uterus one hour after delivery, the presence of boggy uterus with either heavy vaginal bleeding or increasing uterine size is suspicious for uterine atony ; 2- Need of additional oxytocics. Secondary outcome measure: Blood loss and hemoglobin concentration were estimated.

Results: There was a significant difference between both groups as regards uterine atony and need for additional oxytocics after delivery. On the other side, there was no significant association between both study groups as regards vaginal bleeding or HB estimation before and after operation or HB difference.

Conclusion: Carbetocin is more potent long acting oxytocic with less need for other additional uterotonic drugs and less occurrence of uterine atony.
\end{abstract}

Key Words: Caesarean section, carbetocin, ergometrine, oxytocin, postpartum hemorrhage.

Received: 13 November 2017, Accepted: 05 December 2017

Corresponding Author: Eman Zein El Abdeen, Department of Obstetrics and Gynecology, Faculty of Medicine, Beni-Suef University, Egypt, Tel.: 01001458719, E-mail: dremanfarid71@hotmail.com

ISSN: 2090-7265, February 2018, Vol.8, No.1

\section{INTRODUCTION}

Postpartum hemorrhage (PPH) accounts for nearly one quarter of all maternal deaths worldwide ${ }^{[1]}$ and was the second frequent cause of maternal death in the UK during the period the 2000-2002 triennium ${ }^{[2]}$. In developing countries, PPH is estimated to be responsible for about $28 \%$ of maternal deaths ${ }^{[3]}$. This is because high multiparty, prolonged labor, fibroids and severe anemia (probably caused by close spacing of pregnancies, poor diet or parasitic infections) are common ${ }^{[4]}$.

Caesarean section is a recognized risk factor for PPH5 and the worldwide caesarean delivery rate is increasing ${ }^{[6]}$. The cesarean section is a bloody operation, about 750 to $1000 \mathrm{ml}$ are lost at most operations and over $1000 \mathrm{ml}$ of blood have lost to bring them into the definition of a postpartum hemorrhage (PPH $)^{[7]}$. In developing countries, $\mathrm{PPH}$ is the main cause of maternal deaths.Uterine atony is the most common cause of immediate heavy $\mathrm{PPH}^{[8]}$. The administration of oxytocics after the delivery of the neonate reduces the likelihood of $\mathrm{PPH}^{[9]}$ and $5 \mathrm{IU}$ oxytocin by slow intravenous injection is currently recommended for all caesarean sections ${ }^{[10]}$. However, the use of additional oxytocic medication is common, to arrest bleeding, or prophylactically if there are risk factors for $\mathrm{PPH}^{[11]}$ Carbetocin is a synthetic analogue of human oxytocin with structural modifications that increase its half life, thereby prolonging its pharmacological effects ${ }^{[12]}$. Carbetocin has been approved in 23 countries for prevention of uterine atony and excessive bleeding following caesarean delivery in spinal or epidural anesthesia ${ }^{[13]}$.

Oxytocin is a peptide of nine amino acids (Nona peptide). The structure of oxytocin is very similar to that of arginine vasopressin, whose sequence differs from oxytocin by 2 amino acids ${ }^{[14]}$. The best known mechanism for oxytocin to exert its stimulatory effect on myometrial contractility is by increasing the intracellular concentration of calcium ${ }^{[15]}$. Owing to its short plasma half-life (mean $3 \mathrm{~min}$ ), a continuous intravenous infusion is required in order to maintain the uterus in a contracted state. The 
usual dose is $20 \mathrm{IU}$ in $500 \mathrm{ml}$ of crystalloid solution, with the dosage rate adjusted according to response ${ }^{[16]}$.

Ergometrine is a selective and moderately potent tryptaminergic receptor antagonist in various smooth muscles, being only a partially agonistic or antagonistic at tryptaminergic receptors in the central nervous system. In blood vessels, the alkaloid is only weakly antagonistic of dopaminergic receptors and partially agonistic of $\alpha$-adrenergic receptors ${ }^{[17]}$.

A study investigated the efficacy of carbetocin vs. oxytocin for prevention of uterine atony in high-risk women undergoing delivery by caesarean section. Significantly, fewer women experienced uterine atony after caesarean delivery with carbetocin (8\%) vs. oxytocin (19\%). Blood loss $>500 \mathrm{ml}$ was only observed in women who received oxytocin $^{[18]}$. In our study, we investigated the efficacy of carbetocin vs. oxytocin and ergometrine for prevention of $\mathrm{PPH}$ in women undergoing caesarean section.

\section{PATEINTS AND METHODS}

This prospective randomized observational study which took place in Beni-Suef University Teaching Hospital in 2014 was conducted on 200 women with a singleton term pregnancy undergoing elective caesarean section. Women with multiple gestation, placenta praevia and placental abruption were excluded because there is a higher risk of hemorrhage with these conditions and it was therefore felt to be inappropriate to recruit these women. Women undergoing caesarean section with general anesthesia were also excluded, because carbetocin is licensed for use with regional anesthesia only. Furthermore, we excluded women undergoing caesarean section at less than 37 weeks of gestation (likely to be emergency caesarean sections; a different smaller group from term pregnancies) and women having emergency caesarean section for fetal or maternal distress where, due to time constraints, it was not possible and/or appropriate to recruit or randomize.

Women included in the study were divided into 2 groups: Group (A): included 100 patients who received carbetocin $100 \mu \mathrm{g}$ diluted in $10 \mathrm{ml}$ normal saline and administered slowly (over 30-60 seconds) intravenously by anesthetist after birth of the baby. Group (B): included 100 patients who received a combination of intraoperative oxytocin 5 I.U which was diluted in $10 \mathrm{ml}$ normal saline and administered slowly over (30-60 seconds) intravenously by anesthetist and intramuscular ergometrine $0.2 \mathrm{mg}$. The slow administration has been shown to reduce the potentially harmful hemodynamic effects of oxytocin ${ }^{[19,20]}$ (and presumably carbetocin). Also, intramuscular injection of ergometrine did the same. All women were subjected to full history taking, general and obstetric examination and investigations in the form of preoperative routine labs and obstetric ultrasound, and postoperative serum hemoglobin $\%$.

In all cases, approved ethical committee and patients' verbal consent were taken, information sheet was completed included age, parity, gestational age at delivery, also BMI and hemoglobin concentration noted before cesarean sections and 24 hours post partum. The differences between pre- and post C.S values were calculated in each group.

Primary outcome included uterine tone was assessed by using a hand resting on the fundus and palpating the anterior wall of the uterus. The presence of a boggy uterus with either heavy vaginal bleeding or increasing uterine height can suspect the diagnosis of uterine atony. Also, the need for additional oxytocic drug in each group population was reported and tabulated as a primary outcome. Secondary outcome included blood loss which was estimated postoperatively by giving each woman of each group standard 2 dressings (standard weight of dressing is $25 \mathrm{gm}$ ) during $24 \mathrm{hrs}$ postoperative hospital stay and recording weight of blood soaked dressings and volume of lost blood.

The volume of lost blood was estimated by:

1) Weighing the soaked dressings which were prepared for the study as following:

-Weight of blood in a dressing in grams = weight of dressing after removal - weight before application (about 25gm)

-Volume of lost blood in $\mathrm{ml}=$ weight of blood in dressings in gm / 1.06 Where (1.06) is the density of whole blood. It's assumed that weight is due only to blood and not environmental water or debris ${ }^{[21]}$

2) Changes in hemoglobin concentrations before and 24 hours postoperative were estimated. All the resulting data from the two groups collected tabulated and analyzed statistically.

\section{Statistical analysis:}

Data was statistically described in terms of mean \pm standard deviation $( \pm$ SD) or frequencies (number of cases) and percentages when appropriate. Comparison of numerical variables between the study groups was done using 2 tailed independent $t$ tests. For comparing categorical data, Chi square $\left(\mathrm{X}^{2}\right)$ test was performed. Exact test was used instead when the expected frequency is less than 5. $P$ values less than 0.05 was considered statistically significant. All statistical calculations were done using computer program SPSS (Statistical Package for the Social Science; SPSS Inc., Chicago, IL, USA) release 15 for Microsoft Windows.

\section{RESULTS}

That study was conducted on 200 pregnant women at gestational age $\geq 37$ weeks undergoing elective caesarean section. Women were divided into two groups. Group A included 100 women received intravenous carbetocin. Their mean age was $(29.73 \pm 6.27)$ years, mean parity of $(0.77 \pm 1.00)$, mean gravidity of $(1.38 \pm 1.09)$, mean gestational age $(\mathrm{GA})$ was $(38.61 \pm 1.11)$ and mean BMI of 
(25.28 \pm 3.41$)$, as well as 100 pregnant women( $\geq 37$ weeks) (group B) who received a combination of intravenous oxytocin and intramuscular ergometrine. Their mean age, parity, gravidity, GA and BMI was (29.57 \pm 6.19$)$, (0.65 \pm 0.83$),(1.37 \pm 1.06),(38.31 \pm 1.11)$ and $(25.21 \pm 3.28)$, respectively. There were no significant differences between the study groups concerning the age, gravidity, parity, gestational age and BMI (Table 1)

Table1: Baseline characteristics of the study groups

\begin{tabular}{lccc}
\hline & $\begin{array}{c}\text { Carbetocin } \\
\text { group } \\
(\mathrm{n}=100)\end{array}$ & $\begin{array}{c}\text { Oxytocin+ } \\
\text { Ergometrine } \\
\text { group } \\
(\mathrm{n}=100)\end{array}$ & P value \\
\hline Age & $29.73 \pm 6.27$ & $29.57 \pm 6.19$ & $0.85 \mathrm{NS}$ \\
Gravidity & $1.38 \pm 1.09$ & $1.37 \pm 1.06$ & $0.94 \mathrm{NS}$ \\
Parity & $0.77 \pm 1.00$ & $0.65 \pm 0.83$ & $0.35 \mathrm{NS}$ \\
Gestational & $38.61 \pm 1.11$ & $38.31 \pm 1.11$ & $0.59 \mathrm{NS}$ \\
age & & & \\
BMI & $25.28 \pm 3.41$ & $25.21 \pm 3.28$ & $0.88 \mathrm{NS}$ \\
\hline
\end{tabular}

Data are presented as mean \pm S.D.

N.S: Nonsignificant

It was found that uterine atony occurred more in women in the group who received oxytocin with ergometrine (39\%) in comparison to carbetocin group $(21 \%)$. It was obvious that oxytocin group needed more oxytocics than carbetocin group. There was a significant association between both groups as regards uterine atony and the need for oxytocics in which $P$ value was 0.005 and 0.002 , respectively (Table II).

Table II: The results of the primary outcomes

\begin{tabular}{|c|c|c|c|c|}
\hline & Carbetocin & Oxytocin & Total & $\begin{array}{c}\mathrm{P} \\
\text { value }\end{array}$ \\
\hline $\begin{array}{l}\text { Uterine } \\
\text { atony } \\
\text { No }\end{array}$ & $79 \%$ & $61 \%$ & $14070 \%$ & $0.005^{*}$ \\
\hline Yes & $21 \%$ & $39 \%$ & $6030 \%$ & \\
\hline $\begin{array}{l}\text { Need of } \\
\text { oxytocics } \\
\text { No }\end{array}$ & $73 \%$ & $52 \%$ & $12562.5 \%$ & \\
\hline Yes & $27 \%$ & $48 \%$ & $7537.5 \%$ & $0.002 *$ \\
\hline
\end{tabular}

It was found that there was significant association as regards vaginal bleeding between both groups as the mean was $(448.50 \pm 85.11)$ in carbetocin as compared with the mean in oxytocin group was $(505.05 \pm 111.05)$ at $p$ value $<0.001$. As regards, HB before operation, the mean in carbetocin group was $(11.69 \pm 0.88)$; while in oxytocin group, the mean was $(11.53 \pm 0.85)$ with no significant association between both groups. The mean of HB 24 hours after operation in carbetocin group was $(11.18 \pm 0.94)$; while in the other group, the mean was $(10.98 \pm 0.91)$ with no significant association. In carbetocin group the mean regarding HB difference was $(0.51 \pm 0.26)$ while in oxytocin group the mean was $(0.54 \pm 0.30)$ with no significant association. (Table III).

Table III: The results for secondary outcomes

\begin{tabular}{llll}
\hline & $\begin{array}{l}\text { Carbetocin } \\
(\mathrm{n}=100)\end{array}$ & $\begin{array}{l}\text { Oxytocin+ } \\
\text { Ergometrine } \\
(\mathrm{n}=100)\end{array}$ & P value \\
\hline $\begin{array}{l}\text { Vaginal } \\
\text { Bleeding }\end{array}$ & $448.50 \pm 85.11$ & $505.05 \pm 111.05$ & $<0.001^{*}$ \\
$\begin{array}{l}\text { HB_before } \\
\text { operation }\end{array}$ & $11.69 \pm 0.88$ & $11.53 \pm 0.85$ & $0.18 \mathrm{NS}$ \\
$\begin{array}{l}\text { HB_24 hrs } \\
\text { after }\end{array}$ & $11.18 \pm 0.94$ & $10.98 \pm 0.91$ & $0.14 \mathrm{NS}$ \\
$\begin{array}{l}\text { HB_- } \\
\text { difference }\end{array}$ & $0.51 \pm 0.26$ & $0.54 \pm 0.30$ & $0.50 \mathrm{NS}$ \\
\hline
\end{tabular}

Data are presented as mean + S.D.

N.S: Non significant

* Statistically significant

\section{DISCUSSION}

A cesarean section is an invasive surgical procedure in which a baby is delivered through an abdominal and uterine incision, carries with it many immediate and delayed morbidity and mortality risks ${ }^{[22]}$. The cesarean section is a bloody operation, about 750 to $1000 \mathrm{ml}$ are lost at most operations and over $1000 \mathrm{ml}$ of blood have lost to bring them into the definition of a postpartum hemorrhage $(\mathrm{PPH})^{[7]}$. The third stage of labor is potentially the most dangerous part for the mother, and active management may be necessary, i.e. administration of an uterotonic medication before the placenta is delivered ${ }^{[14]}$. Uterine atony is the commonest cause of primary PPH. Risk factors for uterine atony include uterine over distention (multiple gestation, polyhydramnios, fetal macrosomia), prolonged oxytocin use, abnormal labor, grand multiparity, chorioamnionitis, placenta previa, and use of uterinerelaxing agents (tocolytic therapy, halogenated anesthetics, nitroglycerin $)^{[23]}$.

The routine use of oxytocic drugs in association with the management of the postpartum period reduces 
incidence of $\mathrm{PPH}$ up to $40 \%$ of the total cases of $\mathrm{PPH}^{[24]}$. Several uterotonic agents can be used for prevention and treatment of postpartum hemorrhage including Oxytocin, Ergot alkaloids, Syntometrine and Prostaglandins ${ }^{[25]}$.

Carbetocin is a long-acting oxytocin studied by Dansereau et al 1999; they found that the carbetocin group of patients had a decreased incidence of PPH and need for therapeutic oxytocics. The recommended dose of carbetocin is $100 \mu \mathrm{g}$ given either IM or slowly IV (over 1 minute) ${ }^{[26]}$. Our study compared between women undergoing cesarean delivery taking carbetocin and those receiving a combination of oxytocin and ergometrine for prevention of PPH.

Our study showed that the results of comparison between two groups as regards the mean values of baseline characteristics were statistically non significant. As regards uterine atony in both groups, there was a significant association. In carbetocin group, only $21 \%$ of women suffered uterine atony, while $39 \%$ in oxytocin+ergometrine group. The need for additional oxytocic drugs and vaginal bleeding showed also significant association between both groups. However, pre-operative and postoperative $\mathrm{HB}$ or $\mathrm{HB}$ difference showed no significant association between both groups. Oxytocic drugs were needed in $27 \%$ of carbetocin group women, while $48 \%$ of oxytocin+ergometrine group needed additional uterotonic drugs. The mean for vaginal bleeding in carbetocin group was (448.50 \pm 85.11$)$ while that of oxytocin+ergometrine group was (505.05 \pm 111.05$)$.

Some studies were in agreement with our study concerning need for additional uterotonic drugs. Authors compared between carbetocin and oxytocin concerning the need for additional uterotonic drugs. They found significant association between both groups ${ }^{[26,27,28]}$. However, when they tested the need for additional uterotonic agents with carbetocin and oxytocin following vaginal deliveries, they found no statistical significance between both groups. This was in agreement with our thesis despite different mode of delivery. Mode of delivery is an important factor that can influence the treatment outcome. Thus, it is recommended to undertake more studies including patients with different modes of delivery and risk factors for $\mathrm{PPH}^{[26,27,28]}$

Concerning pre- and post-operative HB, some authors found that the estimated blood loss in women who underwent cesarean deliveries was more in the oxytocin group. This agreed with our study. There was greater drop in HB in this group. In contrast to our study, in which HB difference between both groups showed no significant association. This difference from our study may be because all above authors used more patients making difference in sample size ${ }^{[29,30,31]}$

As carbetocin appears to have a similar haemodynamic profile to oxytocin (and both appear to have a more 'benign' adverse effect and haemodynamic profile than syntometrine), then carbetocin may become the drug of choice for women who have contraindications to the administration of Syntometrine, such as women with hypertensive disorders of pregnancy and women with cardiac problems $^{[32]}$.

However, we recommend more wide scales of multicentric randomised controlled studies to prove or disprove our study results on carbetocin as along acting synthetic analouge of oxytocin in prophylaxis against atonic postpartum hemorrhage following cesarean sections, mainly for patients with cardiac diseases or hypertension.

\section{CONFLICT OF INTEREST}

There are no conflicts of interest.

\section{REFERENCES}

1. Carroli G, Cuesta C, Abalos E, Gulmezoglu AM. Epidemiology of postpartum haemorrhage: a systematic review. Best Pract Res Clin Obstet Gynaecol 2008; 22:999-1012.

2. Confidential Enquiry into Maternal and Child Health. Why Mothers Die 2000-2002. London, UK: Royal College of Obstetricians and Gynecologists, 2004.

3. World Health Organization (WHO). Managing Complications in Pregnancy and Childbirth (2011), A Guide for Midwives and Doctors. WHO/RHR/00.7. Geneva: WHO: S25-S34.

4. Milman N. postpartum anemia I: definition, prevalence, causes, and consequences. Ann Hematol. 2011 Nov; 90(11):124753-. Epub 2011 Jun 28 .

5. Stones RW, Paterson CM, Saunders NJ. Risk factors for major obstetric haemorrhage. Eur $\mathrm{J}$ Obstet Gynecol Reprod Biol 1993;48:15-8.

6. Villar J, Valladares E, Wojdyla D, Zavaleta N, Carroli G, Velazco A, et al. Caesarean delivery rates and pregnancy outcomes: the 2005 WHO global survey on maternal and perinatal health in Latin America. Lancet 2006;367:1819-29.

7. Varatharajan L, Chandraharan E, Sutton J, Lowe V, Arulkumaran S. Outcome of the management of massive postpartum hemorrhage using the algorithm "HEMOSTASIS".Int J Gynaecol Obstet. 2011 May;113(2):1524-. Epub 2011 Mar 10. St George's University, London, UK.

8. Prendiville WJ, Elbourne D, McDonald SJ. (2009), WITHDRAWN: Active versus expectant management in the third stage of labour. Cochrane 
Database Syst Rev. 2009 Jul 8 ;(3):CD000007. Department of Obstetrics and Gynaecology, Coombe Lying-In Hospital, Dolphin's Barn, Dublin 8, Ireland.

9. National Collaborating Centre for Women's and Children's Health. Intrapartum Care: Care of Healthy Women and their Babies During Childbirth. London: NICE, 2007.

10. National Collaborating Centre for Women's and Children's Health. Caesarean Section. London: NICE, 2004.

11. Wedisinghe L, Macleod M, Murphy DJ. Use of oxytocin to prevent haemorrhage at caesarean section - a survey of practice in the United Kingdom. Eur J Obstet Gynecol Reprod Biol 2008;137:27-30.

12. Sweeney G, Holbrook AM, Levine M, Yip M, Alfreddson K, Cappi S, et al. Pharmacokinetics of carbetocin, a long-acting oxytocin analogue, in nonpregnant women. Curr Ther Res 1990;47:528-40.

13. Dansereau J, Joshi AK, Helewa ME, Doran TA, Lange IR, Luther ER, et al. Double-blind comparison of carbetocin versus oxytocin in prevention of uterine atony after cesarean section. Am J Obstet Gynecol 1999; 180:670-6.

14. Belghiti J, Kayem G, Dupont C, Rudigoz RC, BouvierColle MH, Deneux-Tharaux C., Oxytocin during labour and risk of severe postpartum haemorrhage: a population-based, cohort-nested case-control study. BMJ Open. 2011 Dec 21;1(2):e000514. INSERM U953 Epidemiological Research Unit on Perinatal Health and Women's and Children's Health, Université Pierre et Marie Curie Paris 6, Paris, France.

15. Su CW. Postpartum hemorrhage. Prim Care. 2012 ; 39(1):167-87. Department of Obstetrics \& Gynecology, Contra Costa Regional Medical Center, 2500 Alhambra Avenue, Martinez, CA 94553, USA.

16. Norgaard, Sorensen,Markova, V., J. L., Holm, C., A. and Langhoff-Ross, J., :Evaluation of multiprofessional obstetric skills training for postpartum hemorrhage. Acta Obstetricia et Gynecologica Scandinavica, 2012; 91: 346-352.

17. Daniel Karila-Kohen, Eric Debly et al: Influence of the endothelium, nitric oxide and serotonergic receptors on coronary vasomotor responses evoked by ergonovine in conscious dogs. Br J Pharmacol. Jun 1999; 127(4): 1039-1047.
18. Del Angel-Garcia G, Garcia-Contreras F, ConstantinoCasas $\mathrm{P}$, et al. Economic evaluation of carbetocin for the prevention of uterine atony in patients with risk factors in Mexico. Value Health 2006; 9(6):A254.

19. Weis FR Jr, Markello R, Mo B, Bochiechio P. Cardiovascular effects of oxytocin. Obstet Gynecol 1975;46:211-4.

20. Thomas JS, Koh SH, Cooper GM. Haemodynamic effects of oxytocin given as i.v. bolus or infusion on women undergoing Caesarean section. Br J Anaesth 2007; 98:116-9.

21. The eighth report of the confidential enquiries into maternal deaths in the United Kingdom. . BJOG, 118(Suppl. 1) (2011) ), pp. 71-76

22. Shelton, D.L. C-sections increasing as doctors, patients reevaluate the risks. American Medical News. 9 Oct 2011.

23. Geary M, Rizvi F, Mackey R, Barrett T and Mackenna $\mathrm{P}$ : successful reduction of massive postpartum hemorrhage by use of guidelines and staff education. BJOG 2011; 111 (5): 495-8

24. Hutchon DR,Soltani H, Poulose TA. Timing of prophylactic uterotonics for the third stage of labour after cesarean section. Cochrane Database Syst Rev. 2010 Aug 4;(8):CD006173. Faculty of Health and Wellbeing, Sheffield Hallam University, Sheffield, UK, S10 2BP.

25. World Health Organization: Guidelines for the prevention of postpartum haemorrhage. Geneva: 2007, 2010, 2011.

26. Dansereau J, Joshi AK, Helewa ME, Doran TA, Lange IR, Luther ER, et al. Double-blind comparison of carbetocin versus oxytocin in prevention of uterine atony after cesarean section. Am J Obstet Gynecol 1999;180(3 Pt1):670-6

27. Borruto F, Treisser A, Comparetto C. Utilization of carbetocin for prevention of postpartum hemorrhage after cesarean section: a randomized clinical trial. Archives of Gynecology and Obstetrics 2009;280(5):707-12.

28. Boucher M,Horbay GL, Griffin P, Deschamps Y, Desjardins C, Schulz M, et al. Double-blind, randomized comparison of the effect of carbetocin and oxytocin on intraoperative blood loss and uterine tone of patients undergoing caesarean section. Journal of Perinatology 1998;18(3):202-7. 
29. Askar AA, Ismail MT, El-Ezz AA, Rabie NH. Carbetocin versus syntometrine in the management of third stage of labor following vaginal delivery. Archives of Gynecology and Obstetrics 2011;284(6):1359-65.

30. Attilakos G, Psaroudakis D, Ash J, Buchanan R, Winter C, Donald F, et al. Can a new oxytocin analogue reduce the need for additional oxytocics after caesarean section? The results of a double-blind randomized trial. Archives of Disease in Childhood. Fetal and Neonatal Edition 2008;93

31. Boucher M. Carbetocin IM injection vs oxytocin IV infusion for prevention of postpartum hemorrhage in women at risk following vaginal delivery. Journal of Obstetrics and Gynecology Canada: JOGC 2003;25 